\title{
Chat as Media in Exams
}

\author{
Claus Witfelt, Poul Erik Philipsen and Birte Kaiser \\ Danish University of Education, Emdrupvej 101, DK-2400 NV, Denmark \\ clw@dpu.dk \\ CVU-Vest, Hammerum Hovedgade 7, DK-7400 Herning, Denmark \\ CVU-Vest, Skolebakken 171, DK-6505 Esbjerg S, Denmark
}

Keywords: distance learming, further education, assessment, open flexible learning

\begin{abstract}
The paper reportsdocuments our experiences using chat as a medium for exams in a so-called flexible education. The type of education is adult learning and planning of education. The experiences show some interesting results. It is a very different way of communicating, which leaves a new level of initiative and control to the student. A new way of assessment has qualified the study process, and this work has examined one way to do virtual assessment.
\end{abstract}

\section{INTRODUCTION}

The Voksplan education is a flexible version of the Danish diplomadegree in adult learning and educational planning. By flexible we mean delivered with ordinary teaching sessions combined with learning via the Internet and electronic conferences. ICT should be a predominant and natural part of the education. Accordingly, we wanted to investigate how exams could also be held via ICT.

To many people, chatting suggests the notion of non-serious, very light discussions, often without deeper meaning. However, our experiences as teachers from other flexible courses and education was that chat can be used for discussing serious issues as well - with very good results. But in order to turn chat into a valuable tool, the users need to develop a special language, as is the case with any other media. We wanted to stimulate the students to 
do this and to test chat as a media for serious discussions by using chat as a media for exams. This paper documents our experiences with this experiment.The development of this special version of the diplomaeducation has been supported by CTU Denmark's National Information Centre for Technology Supported Learning. The Voksplan education itself has earlier been documented in a series of papers [http://www.dpu.dk/voksplan]. The authors are both the developers of the curriulum and the teachers.

\section{THE HISTORY OF CHAT AS MEDIA IN EXAMS}

On several earlier occasions, we found that the students made good use of the chat functions in electronic conferencing environments like FirstClass and Webboard. They typically used chat when the normal, asynchronous conferencing facilities got too tedious. When arrangements about when to meet face-to-face, were to be made, chat was used. On the LINK-course, featured chats were arranged where the participants could chat with the authors and speakers about certain topics, for instance organisational change. We were inspired by the media, but felt that it could be used and exploited further.

The whole development of the flexible version of the traditional diplomaeducation was already in process, but still it had to be approved by the board in charge of the adult teaching in the Danish University of Education. But as chat has a non-serious reputation, this was not an easy quest. Could serious discussions be held via chat? Could we be sure that there was only one present in the room, when the students were examined? Were we sure that it was the actual person we were chatting with? In the official description of the education, we had to change the word 'chat' into synchronous Internetbased communication, in order to have it approved.

We did not intend to force anyone to graduate using this media, if they did not want to do it, but the majority of the students chose to participate in the experiment. Almost all of the students were teachers themselves, and they found it interesting to participate.

Immediately after the first exam, several of the students claimed that they did not want to participate. Some argued that they could not see the difference, whether you discussed live or via chat. Some did not see the point in examining via chat, and others presented arguments which could hide fear for not being able to get good grades via this new kind of exam. However as time passed and the students practised with the chat and got used to the idea, most of the students decided to take part in the experiment. 
The majority of the students were very enthusiastic about the idea of chat-exams, as it fits a flexible course. The seminars take place in Herning, about 400 kilometres from Copenhagen. Many of the students found that it was a good thing not to have to take the trip all the way to Herning, 'just' to pass an exam. Another argument was that if chat-exams constituted a new way to graduate students, they better try it as students, so they could use it themselves in their own courses. 9 chose to try the chat-exam; 5 chose the traditional exam. The chat-exam came out with grades on the same level as the traditional versions of the module in this diploma-education, between 7 and 11. (In the Danish grade-system, 00 is lowest, 13 is highest, so 7 is average as 11 very good).

\section{WRITTEN OR ORAL MEDIA?}

Is chat an oral or written media? Are chat-exams written exams or oral? The word chat suggests something oral, but you communicate with the keyboard, so seen from a technical point of view it is a written media. Seen as a genre, chat is most definitely an oral media. You use quick, very simple sentences and often smileys and abbreviations, for instance, the characteristic acronyms (BTW, LOL). The turn taking is quick too. But, chats do not have to be held in the genre you find in the big, public chatrooms. You can indeed have serious discussions, but our experiences as teachers (we have also used chat for teacher co-operation) are that it takes time to develop a language for this specific media. Our conception of chat is that it is a hybrid between written and oral media. The students as well have to develop a way to use it. However, we realised how difficult this may be; we have decided, however difficult this may be for us, to ignore spelling errors, bad language.

One of the problems that teachers as well as students must face, and find solutions to, is pauses. Are the students expecting anything? Are the teachers? Will the student come up with more or is it time to pose a new question? Another problem is the role of the teacher; should they take the initiative during the exam or should the students? What happens in case of technical problems?

\section{ABOUT THE CHAT}

We used the chat function, which is built into the conference-system that is used as standard on the Danish University of Education, that is a version of O'Reilly's Webboard. This chat is very similar to other chat-functions, for 
instance in FirstClass. This chat is not very advanced, but it works. The major disadvantage is that it is not possible to make postings of more than 500 characters. As a backup against system-breakdowns, we also supplied a small web-based chat, based on Info-Chat.

All the way through their education, the students have been stimulated to use chat. They were taught the functions of the system and some students have used it a lot. On their own initiative, they held exams in order to practice using this media. Some groups have not used the chat, some have not even used the conference, but all tried during the second module to chat, so as to gain experiences with the chat in order to be able to pass an exam.

Because it was a development process it was decided that both the examiners, internal and external, should sit in the same room in the location in Herning, so they could discuss face-to-face and use a high-capacity connection to the Internet. The chat was to be held on basis of a synopsis, a written essay of a maximum of 20 pages. The students developed the work in teams, but wrote their own synopses. Both the external and internal examiner received the synopsis in time for reading.

\section{A LANGUAGE FOR THE CHAT-MEDIA}

We believe that for every media you need to develop a special language. This is also our experience with chat. You can only develop this special language by practising, i.e. by chatting. Both teachers and students need to use the media in order to experience possibilities and drawbacks with the media and find solutions to the problems. An example of such a problem is the 500 character limitation. Chat is normally only used for one-line comments, but in our case we needed also to use the compose function that allows the chatters to compose messages of up to 500 characters. This helps, but even 500 characters are not enough, if you want to get into depth with something - as in our exams.

The students who had chatted a lot had already developed solutions to some of the problems, for instance the question of more text being on the way. If nothing was done, the examiner posed new questions, which resulted in several questions being 'in the air' at one time.

We wish to share what we have learnt by studying the behaviour and habits of experienced chatters in the large, public chatpools 


\section{TO BE ICT-LITERATE OR NOT...}

It is not necessary to be ICT literate when you start the Voksplan education. On the contrary we use a lot of energy in training the students to get them well off the ground with the technology. All the same, they must develop their ICT-skills during the education, in order to be able to fulfil the goals of the education. To avoid very ICT literates having an advantage over non-ICT literates, we made the exam non-mandatory.

Already in the initial seminar we use a whole day to introduce the students to the Voksplan website, how to work in conferences and to moderate conferences, how to chat. All these competences that we consider a natural part of ICT-literacy. Accordingly the students should have equal terms for passing this exam. It was quite evident however, that those students who had practised a lot with chatting and used it in their everyday studies and even had made exams were much better than those, that had not done so. An interesting question is, what would have happened, if chatexams were used as a media with youngsters, that have used chat the way adults have used the phone? Other investigations have to uncover this.

\section{THE EXPERIENCES}

We experienced, that the groups that had used the chat a lot and made test chat-exams behaved more naturally in the chat environment. To many of our students, the Voksplan education was their first chat-experience. Therefore, it could be interesting to carry through a chat exam with children who are very used to chatting everyday.

Obviously, it is much slower to write than to talk, but the examiner had plenty of time, whereas the students felt an extreme time pressure. As one student put it: "You have so very little time. Chat-exams must simply take more time than normal exams". An answer that takes 10 minutes to compose, can be read in 10 seconds, so the examiner/censor will have to be patient.

Body language does not exist in chat-exams. This is a two-edged sword. It is nice, because the examiner cannot see the student, and grades are given alone on basis of the synopsis and what is written in the chat, but from a communicative point of view much is lacking. Another problem is the small ansynchonicity. Chat is a synchronous media, but since it takes longer to write than to discuss orally, two questions can be discussed at the same time, but which can raise the stress level. 
After the chat-exam, we asked the students about their experiences with chat-exam in the conference-system. The following all originates from these interviews.

Some find that the fear of exams has gone, because you are at home, less stressed and you do not have to think about your body-language. However, there are also drawbacks. The feeling of closeness has gone and at times, there is more than one question at a time, which increases the stress-level. One of the students reported that it was a huge advantage to have tried to be 'chat-examiner' before being examined, because you recognize the problems and know how short of time you feel you have.

Is this kind of exam really well suited for an education like Voksplan, where there are no correct answers, but instead discussions of attitudes, values and aesthetic learning processes? At first you might think that this was the case, since chat is normally used for discussions, but both the examiners and the students report problems with getting into depth with the issues discussed (Kaiser and Philipsen 2000). Our data is too limited for us to conclude upon this, but it seems as if chat could be used better with exams in more factual themes. One student report: "It is difficult to get dialogue at a higher level than 'teacher asks - student answers'. It was also difficult to get into more theoretical issues".

Both internal examiners told us that they had initially discussed with the students how many items to discuss and that they would tell the students, when they changed subject. This was a way to ensure that there was time enough to get into depth with the issues raised.

\section{INITIATIVE AND CONTROL}

When using chat as teacher-communication media, the teacher-group itself experienced that chat is much slower than ordinary dialogue or videoconferencing. Furthermore we found out that it is more difficult to locate where the dialogue is heading and to get into depth with the issues discussed. To help the students overcome these problems we decided that the examiner should lead the dialogue. In this way we hoped that the control of understanding could be better. Furthermore it was an advantage that the students were examined in a synopsis, a short 10 pages of text. This limited the amount of topics.

The question about who is taking the initiative in the dialogue is interesting. The students possess a lot of possibilities for controlling the exam, that do not exist in normal exams. As one on the examiners put it "The students are more in control. You cannot as easily interrupt in the dialogue" (Kaiser and Philipsen 2000). Another examiner felt that (s)he 
should interrupt and have control. Therefore he has typed some questions in a file, in order to easily pose the questions. This helped the examiner to control the exam and avoid the more chatting-style communication.

Both the examiners and students that have tried out the testexams report back, that it is very much the students, who have the initiative. One examinator reported "I had to be extremely well prepared, if I wanted to gain control over the exam" (Kaiser 2000). A student reported "As the student, that is examined, the codewords are: Fire at will."

\section{CONCLUSION}

There are many things at stake, when one decides to use chat as media in exams. We have chosen to discuss 2 issues. Is this a new future form for exam? Can this new, radically different way of doing exams teach us something about the normal way we do exams?

\subsection{Chat-exams - the exam form of the future?}

Our data are too sparse to conclude, whether this is a new way of carrying out exams, but our students were very enthusiastic about this form. We think it was a good experience and we intend to offer future classes the possibility of doing chat-exams, in order to learn more about it. But much more, we want to gain experience about a very different way to do exams to tell us something about our normal of doing exams.

There are a lot of unsolved questions, like what happens, if the system breaks down under the exam? Are the students allowed to pass another then? We need to develop new ways to do exams in flexible environments. It has been interesting to test new forms of exams, especially as in this case, where some of the power is moved from the examiner to the student. We need to know a lot more about it, for instance how to train the students better towards developing a language for interacting in the chatroom.

Furthermore it has been interesting to work with a form that creates a more fluent study form and a greater coherence between form of study and form of examination. We hope that this idea could inspire more course and educational designers.

\subsection{Chat-exams and traditional exams}

Doing the chat-exam forced us to pose the fundamental question: What is basically an exam? Is an exam solely an evaluation or should it rather be an 
experience, where experts from outside the institution give their comments on the work done? Is it just the 20 last minutes of a project or an integrated part of a longer competence-development.

We find that the most important answer to this is that by making exams and study-forms more equal, we approach the last goal. We force the students to develop the study competences (chat) by making it mandatory in the end. When we are working in a flexible learning environment, we also test the student's study-competence when using chat-exams.

We have experienced and the students report back that they find it difficult to act convincingly, but this might, after all, just be a question of gaining enough experience with the chat.

\subsection{Future chat-exams}

The next class has not yet reached the 2nd module, where the chat-exam is a possibility, but we have emphasised chat much more in the initial seminar, where the students get a whole day introduction to the electronic conferences, chat etc. These students use chat much more to discuss, than ordinary electronic conferences, which are mostly used as a virtual library. In the first class, the students used the conferences very actively as discussion media and only a few of the groups chatted regularly. To us, this is a very important reason why one should consider doing exams via the chat: Approaching the exam form in the way the students study, forces the student to work with the media. The exam helped them qualify their study process.

\section{REFERENCES}

Kaiser, B (2000) Evaluation note about testexam by Birthe Kaiser, teacher, Esbjerg.

Kaiser, B. and Jørgensen, B. (2000) Mennesket er ikke et cesel (Man is not a donkey). DPU, Esbjerg.

Kaiser, B. and Philipsen, P. E. (2000) Interview with Birte Kaiser and Poul Erik Philipsen, August $8^{\text {th }}$,unpublished, Herning.

\section{BIOGRAPHIES}

Claus Witfelt, a researcher at the Danish University of Education, Institute for Curriculum Research, works with flexible learning. Poul Erik Philipsen is a leader of the centre for adult education in CVU Vest, Herning. Birte Kaiser is a teacher and doctoral student at CVU-Vest, Esbjerg. 